\title{
Optimization of ethanol production from Garcinia kola (bitter kola) pulp agrowaste
}

\author{
Humphrey. C. Nzelibe ${ }^{1 \star}$ and Caritas U Okafoagu ${ }^{2}$ \\ ${ }^{1}$ Department of Biochemistry, Ahmadu Bello University, Zaria, Nigeria. \\ ${ }^{2}$ National Agency for Food and Drugs Administration and Control, Kaduna Area, Laboratory, Kaduna.
}

Accepted 19 May, 2007

\begin{abstract}
Optimization options for production of ethanol from bitter kola (Garcinia kola) pulp wastes were investigated. The methods are degumming, saccharification, acid hydrolysis, alkaline hydrolysis. Degumming was effectively achieved at $96 \mathrm{~h}$ of saccaharification. The concentration of reducing sugar for the treated sample (acid hydrolysed and saccharification) and control sample (saccharification) was maximum at $144 \mathrm{~h}(86.2 \mathrm{~g} / 100 \mathrm{~g})$ and $96 \mathrm{~h}(31.5 \mathrm{~g} / 100 \mathrm{~g})$, respectively. Ethanol yield from treated sample and control sample using baker's yeast was maximum at $120 \mathrm{~h}(70.7 \mathrm{~g} / \mathrm{L})$ and $192 \mathrm{~h}(29.3 \mathrm{~g} / \mathrm{L})$, respectively. Alkaline hydrolysis with $0.25 \mathrm{M}$ sodium hydroxide has no significant effect on concentration of reducing sugar and ethanol yield. Acid hydrolysis with $2.5 \mathrm{M}$ sulphuric acid and saccharification using Aspergillus niger are better methods for optimizing ethanol production from bitter kola pulp waste. Solar drying of the bitter kola pulp waste significantly enhanced ethanol production.
\end{abstract}

Key words: Bitter kola pulp wastes, degumming, saccharification, acid hydrolysis, alkaline hydrolysis, fermentation.

\section{INTRODUCTION}

Ethanol is a renewable energy resource produced through fermentation of simple sugars by yeasts. Ethanol is widely used as a partial gasoline replacement in US and other parts of the world such as Canada. It can also be used in a variety of cooking, heating, and lighting appliances. Fuel ethanol that is produced from corn has been used in gasohol or oxygenated fuels since 1980 . Ethanol that is blended directly with gasoline in a mix of $10 \%$ ethanol and $90 \%$ gasoline is called gasohol. Recently, US automobile manufacturers have announced plans to produce significant numbers of flexible-fueled vehicles that can use ethanol blend - E85 (85\% ethanol and $15 \%$ gasoline by volume). Demand for ethanol E85 has grown from 144,000 gallons in 1992 to 2 million gallons in 1998. The federal Government of Nigeria has concluded plans to invest 400 Billion Naira (3.5 billion US dollars) in Jigawa State Ethanol production programme to

${ }^{*}$ Corresponding author. E-mail: zeechuks@yahoo.com. Tel: +234. 08036005184. diversify its sources of revenue (THISDAY, 2006). US President, George W Bush, announced in his state of the union speech, an agenda to develop alternative energies such as ethanol from grains and cellulose in order to end Americas dependence on oil (Analyst, 2006). Using ethanol -blended fuel for automobiles can significantly reduce petroleum use and existing greenhouse gas emission (Wang et al., 1999). Ethanol is also a safe alternative to methyl tertiary butyl ether (MTBE), the most common additive to gasoline used to provide cleaner combustion (Mani et. al., 2002). MTBE is a toxic chemical compound and has been found to contaminate groundwater. World's ethanol production was about 29.9 billion liters in 2000, which was less than 31.4 billion liters forecasted (Mani et al., 2002). The benefits of developing biomass-to-ethanol technology are: increased national energy security, reduction in greenhouse gas emissions, use of renewable resources, foundation of a carbohydrate-based chemical process industry, macroeconomic benefits for rural communities and society at large (Wayman et al., 1992).

Lignocellulosic material is a less expensive source of carbon, and includes wheat straw (Doppelbauer et al., 
1987; Abd El-Nasser et al., 1997), sugar cane bagasse (Kawamori et al., 1986; Aiello et al., 1996), aspen wood (San Martin et al., 1986), willow (Reczey et al., 1996) corn cobs (Abd El-Nasser et al., 1997) and waste newspaper (Maheshwari et al., 1994; Chen and Wayman, 1991). However, the necessary pretreatment of raw material also adds to the cost of production (Hsu, 1996). Akin-Osanaiye et al. (2005a) reported ethanol production with Carica papaya wastes. Also the wet sample of bitter kola pulp waste has been used for the production of ethanol (Akin-Osanaiye et al. (2005b). The production of ethanol using molasses have also been reported by Bilford (1942) and Bose and Ghose (1973). Most pretreatment approaches do not hydrolyze significant amount of the cellulose fraction of biomass, pretreatment enables more efficient enzymatic hydrolysis of the cellulose by removal of the surrounding hemicellulose and/or lignin along with modification structure. Current pretreatment research and development activities are geared toward identifying, evaluating, development, and demonstrating promising approaches that primarily support the subsequent enzymatic hydrolysis of the treated biomass. Universal pretreatment process is difficult to envision owing to the diverse nature of biomass. Thus, several physical, chemical and biological treatments are under evaluation. The resulting composition of the treated material is independent on the sources of the biomass and the type of treatment, but in general, is much more amenable to enzymatic hydrolysis by cellulases and related enzymes than native biomass. Recently we have reported the effect of acid hydrolysis of $G$. kola pulp waste on the production of CM-cellulase and Bglucosidase using Aspergillus niger (Okafoagu and Nzelibe, 2006). The present study was therefore focused on the methods that could optimize ethanol production from bitter kola pulp wastes.

\section{MATERIALS AND METHODS}

G. kola was seperated from the fruit and the pulp waste is discarded after the removal of the seeds. One kilogram of the pulp waste was dried in the solar dryer and ground into powdered form using a blender. The sample was packaged and then stored in the deep freezer at $4^{\circ} \mathrm{C}$. The $A$. niger was isolated from the soil and identified in Microbiology Department Laboratory, Ahmadu Bello University, Zaria. A. niger was added into a freshly prepared potato dextrose agar (PDA) and left for four days. Tween $80(2 \%)$ solution was prepared and sterilized for one hour. A. niger spores were transferred into the solution to get uniform suspension. Number of spores was counted with binocular using haemocytometer, and the spore load per $\mathrm{ml}$ was counted to be $9.55 \times 10^{7}$.

\section{Chemicals and reagents}

Bakers yeast and EMCEferm instant active yeast were of Saccharomyces cereviscae. Bakers yeast was obtained from Kaduna central market while EMCEferm was obtained from Muhlenchemie cmbh \& co. kg Ahrensburg, Germany. Hydrochloric acid, sulphuric acid, sodium hydroxide, Tween 80 , dinitrosalicylic acid, glucose, arabinose, sucrose and maltose standards, silica gel 60, anhydrous calcium sulphate, chloroform, acetic acid, diphenylamine, acetone, phosphoric acid, aniline potassium sodium tartrate, were of analytical grade and products of British Drug House $(B D H)$ Poole , England and Sigma Chemicals (USA).

\section{Degumming of bitter kola using $\boldsymbol{A}$. niger}

Ten grams of the sample were weighed into five $250 \mathrm{~cm}^{3}$ conical flasks, and $100 \mathrm{~cm}^{3}$ distilled water added respectively. The flasks were covered with aluminum foil and boiled for 5-10 min. The flasks were allowed to cool and $1.0 \mathrm{ml}$ of $9.33 \times 10^{7}$ spores suspension of $A$. niger were added aseptically into each flask except one which was taken as control and kept immediately in the refrigerator. The remaining four flasks were incubated at $30^{\circ} \mathrm{C}$. A flask was removed each day and kept in the refrigerator. At the end of four days the samples and arabinose standard were spotted on thin layer chromatographic plates with the developing solvents (chloroform : acetic acid : water, 6:7:1). After a run, the plates were dried in an oven and the spots were located with the aid of reagent spray. The spotting agent was made up by dissolving one gram diphenylamine and $1 \mathrm{~cm}^{3}$ aniline in $100 \mathrm{ml}$ of acetone prior to spraying). Acetone solution $(10.0 \mathrm{ml})$ was mixed with $1.0 \mathrm{ml} 85 \%$ phosphoric acid. The sprayed plates were heated for $10 \mathrm{~min}$ at $130^{\circ} \mathrm{C}$ in an oven.

\section{Acid hydrolysis and saccharification (Dahot and Noomrio, 1996)}

One hundred grams of dried sample were weighed into two 2000 $\mathrm{cm}^{3}$ conical flasks and $1000 \mathrm{ml}$ of sulphuric acid were added to one conical flask (acid hydrolysed) while $1000 \mathrm{ml}$ distilled water were added to the other (control). The flasks were covered with aluminium foil and heated for two hours on flame and autoclaved for 30 min. The flasks were allowed to cool and filtered through Whatman No.1 filter paper. The $\mathrm{pH}$ was adjusted to 4.5 with $0.4 \mathrm{M}$ sodium hydroxide. Fifty millilitres of solubilized treated sample were added into nine $250 \mathrm{~cm}^{3}$ conical flasks. The flasks were covered with aluminium foil and autoclaved for $20 \mathrm{~min}$ and were allowed to cool at room temperature. One millilitres of $9.33 \times 10^{7}$ spores suspension of $A$. niger were added to each flask and incubated at $30^{\circ} \mathrm{C}$. A flask was removed every twenty-four hour and the concentration of reducing sugar was determined by dinitrosalicylic acid (DNS) method described by Miller (1959). The experiment was carried out in duplicates for nine days. The same was repeated for control sample.

\section{Alkaline hydrolysis}

Alkaline hydrolysis of samples was carried out according to Shipnei et al. (1995). One hundred grams of dried sample were weighed into each of the two $2000 \mathrm{~cm}^{3}$ conical flasks and $1000 \mathrm{~cm}^{3}$ of $0.25 \mathrm{~m}$ sodium hydroxide solution was added to one conical flask (alkaline hydrolysed) while $1000 \mathrm{~cm}^{3}$ of distilled water were added to the other (control). The flasks were left for one hour, after which the mixtures were neutralized with $0.1 \mathrm{M}$ hydrochloric acid (HCL) to a $\mathrm{pH}$ of 4.5. The flasks were allowed to cool at room temperature and filtered through Whatman No.1 filter paper. Fifty millilitres of solubilized alkaline hydrolysed sample was added into nine $250 \mathrm{~cm}^{3}$ conical flask. The flasks were covered with aluminium foil and autoclaved for $20 \mathrm{~min}$ and were allowed to cool at room temperature. One millilitre of $9.33 \times 10^{7}$ spores suspension of $A$. niger were added aseptically to each flask and incubated at $30^{\circ} \mathrm{C}$. The experiment was carried out in duplicates for nine days. The procedure was repeated for control sample. A flask was removed every twenty-four hour and the concentration of reducing sugar was determined by DNS method (Miller, 1959). 


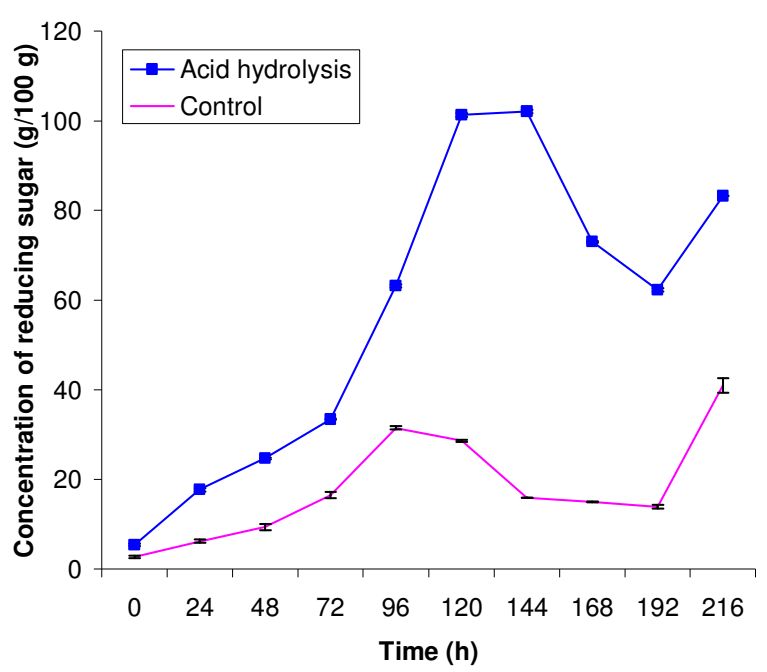

Figure 1. Effect of acid hydrolysis with $2.5 \mathrm{M}$ sulphuric acid, saccharification with Aspergillus niger of bitter kola pulp on concentration of reducing sugar.

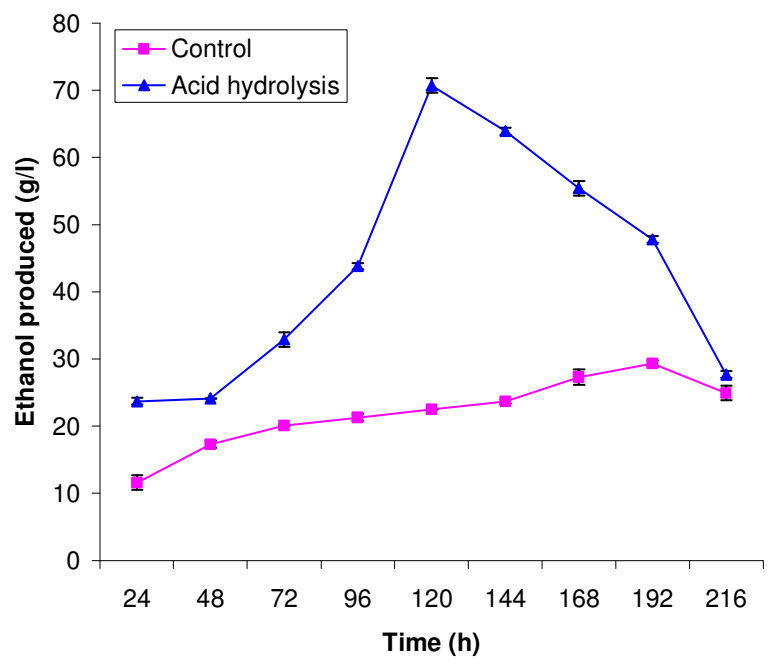

Figure 2. Ethanol produced ( $\mathrm{g} / \mathrm{L})$ after acid hydrolysis with $2.5 \mathrm{M}$ sulphuric acid, saccharification with Aspergillus niger and fermentation of bitter kola pulp using baker's yeast

\section{Fermentation}

Ten grams of the dried sample were weighed into nine $250 \mathrm{~cm}^{3}$ conical flask and $100 \mathrm{ml}$ of distilled water added. The $\mathrm{pH}$ was adjusted to 4.5 with $4.0 \mathrm{ml}$ of $0.4 \mathrm{M}$ sodium hydroxide. The flasks were covered with aluminium foil and hydrolysed for $3 \mathrm{~h}$ with $2.0 \mathrm{M}$ sulphuric acid. The flasks were allowed to cool and baker's yeast $(10 \mathrm{~g})$ was added to each flask and incubated at $30^{\circ} \mathrm{C}$ for nine days. One conical flask was removed every twenty-four hour and contents distilled using distillation column. The distillate was collected at $78^{\circ} \mathrm{C}$ over a slow heat and the volume of ethanol determined is expressed as $\mathrm{g} / \mathrm{L}$ by measuring the volume of distillate at $78^{\circ} \mathrm{C}$ and multiplying by the density of ethanol $(0.8033$ $\mathrm{g} / \mathrm{ml}$ ), $\mathrm{g} / \mathrm{L}$ is equivalent to the yield of $100 \mathrm{~g}$ of dried substrate. Fermentation was carried out in duplicates for nine days. The procedure was repeated using EMCEferm yeast.

\section{Invertase supplementation}

Hundred grams of dried sample were weighed into $2.0 \mathrm{~L}$ conical flasks and $1.0 \mathrm{~L} 2.5 \mathrm{M}$ sulphuric acid was added to one conical flask (acid hydrolysed) while $1.0 \mathrm{~L}$ distilled water was added to the other (control). The flasks were covered with aluminium foil and hydrolysed for three hours on boiling water bath and flasks autoclaved for 30 min were allowed to cool and the sample filtered through Whatman No.1 filter paper. The $\mathrm{pH}$ was adjusted to 4.5 with $0.4 \mathrm{M}$ sodium hydroxide. $50 \mathrm{ml}$ of solubilized acid hydrolysed sample was each added into nine $250 \mathrm{~cm}^{3}$ conical flask. The flasks were covered with aluminium foil and autoclaved for $20 \mathrm{~min}$ and were allowed to cool at room temperature. One millilitre of $9.33 \times 10^{7}$ spores suspension of $A$. niger was added aseptically to each flask and incubated at $30^{\circ} \mathrm{C}$. A flask was removed every twenty-four hour and 1.0 millilitre of digest added into a test tube. One millilitre of $0.1 \%$ invertase was added and the tube was covered with aluminium foil and incubated at $30^{\circ} \mathrm{C}$ for one hour. The concentration of reducing sugar released was determined by DNS method (Miller, 1959). The experiment was carried out for nine days in duplicates. The same was repeated for control samples. The procedure was repeated using maize and rice husks.

\section{RESULTS AND DISCUSSION}

Degumming was optimal at the $96 \mathrm{~h}$ (result not shown). Effect of acid hydrolysis with $2.5 \mathrm{M}$ sulphuric acid and saccharification of bitter kola pulp with $A$. niger on concentration of reducing sugar is shown on Figure 1. The concentration of reducing sugar for treated sample (acid hydrolysed and saccharification) and control sample (saccharification) was maximum at $144 \mathrm{~h}(86.2 \mathrm{~g} / 100 \mathrm{~g})$ and $96 \mathrm{~h}(31.5 \mathrm{~g} / 100 \mathrm{~g})$, respectively. The result obtained with the control sample was higher than what was reported by Akin-Osanaiye et al. (2005b). This could be due to the fact that dried sample was used in this study instead of wet sample. Wet sample might have contained some compounds which act like inhibitors and affects the performance of the micro-organism. The treated sample released the highest fermentable sugar. Perhaps bitter kola pulp waste might have high cellulose and hemicellulose contents and low lignin content. Cellulose is placed beneath the network of lignin and hemicellulose components. Pretreatment or hydrolysis with sulphuric acid may have removed and hydrolysed hemicellulose to their monomeric constituent and lignin-hemicellulosecellulose interactions partially disrupted (Ladisch, 1989; Days, 1989). This pretreatment therefore solubilized the cellulose making it amenable to attack by the cellulase produced by $A$. niger. The acid disrupts the hydrogen bonding between cellulose chains, converting it to a completely amorphous state, thereby forming a homogenous gelatin with the acid. At this point the cellulose is extremely susceptible to hydrolysis (Hsu, 1996). This shows acid hydrolysis significantly $(\mathrm{P}<0.05)$ enhanced saccharification of bitter kola pulp waste with $A$. niger.

Ethanol produced after acid hydrolysis with $2.5 \mathrm{M}$ sulphuric acid and saccharification with $A$. niger and fermentation of bitter kola pulp wastes using baker's yeast is shown on Figure 2. Ethanol produced from treated sam- 


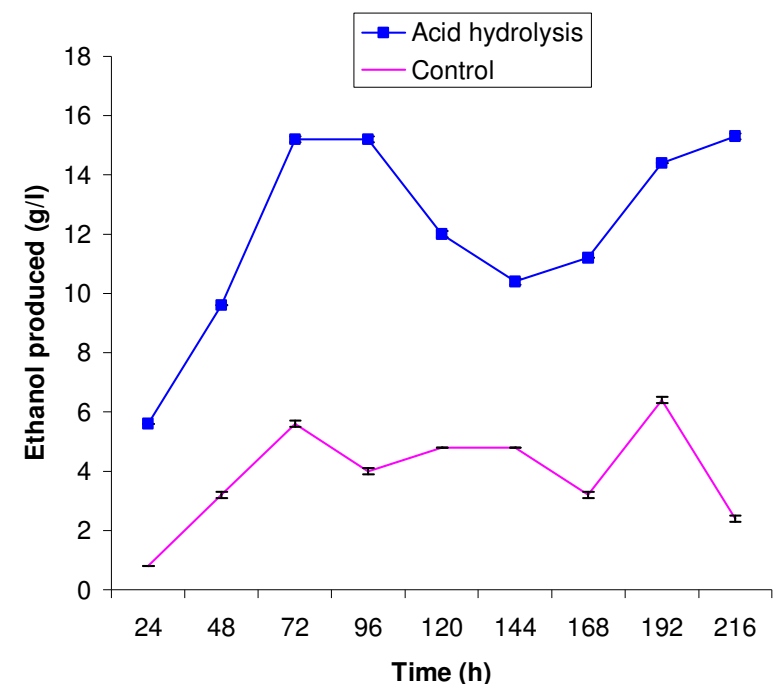

Figure 3. Ethanol produced ( $\mathrm{g} / \mathrm{L})$ after acid hydrolysis with $2.5 \mathrm{M}$ sulphuric acid, saccharification with Aspergillus niger and fermentation of bitter kola pulp using EMCEferm yeast.

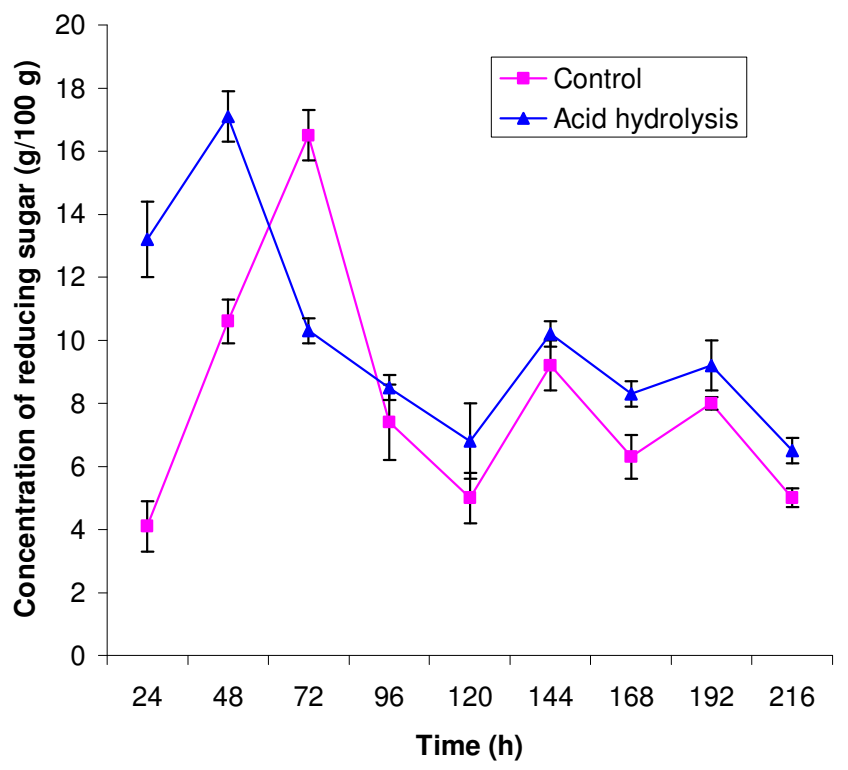

Figure 4. Effect of alkaline hydrolysis ( $0.2 \mathrm{M}$ sodium hydroxide) and saccharification with Aspergillus niger of bitter kola pulp on concentration of reducing sugar.

ple was maximum $(70.7 \mathrm{~g} / \mathrm{L})$ at $120 \mathrm{~h}$ while control value was maximum $(29.3 \mathrm{~g} / \mathrm{L})$ at $192 \mathrm{~h}$. The result obtained with the control sample was higher than that reported by Akin-Osanaiye et al. (2005b). This could be due to the fact that dried sample was used in this study instead of wet sample. Acid hydrolysis significantly $(P<0.05)$ enhanced ethanol yield. Ethanol produced after acid hydro- lysis with $2.5 \mathrm{M}$ sulphuric acid and saccharification with $A$. niger and fermentation of bitter kola pulp wastes using EMCEferm yeast is shown on Figure 3. Two peaks were observed for both treated and control samples. Ethanol produced from treated sample was $11.2 \mathrm{~g} / \mathrm{L}$ at $96 \mathrm{~h}$ and $12.9 \mathrm{~g} / \mathrm{L}$ at $216 \mathrm{~h}$ while control was $5.6 \mathrm{~g} / \mathrm{L}$ at $72 \mathrm{~h}$ and $6.4 \mathrm{~g} / \mathrm{L}$ at $192 \mathrm{~h}$. These values were lower than those produced with baker's yeast. This showed that baker's yeast is a better yeast for fermentation of bitter kola pulp waste. This is in line with the report of Akin-Osanaiye et al. (2005a). The decline and stabilization in ethanol noticed at some stages may be due to the inhibitory effect of ethanol on growth and transport metabolism of the yeast (D'AMarc and Stewart, 1987; Xu, 1996). Conventional yeast can ferment glucose to ethanol, but it cannot ferment xylose. Xylose makes up $30 \%$ of the sugar from agricultural residues, and inability to ferment xylose would constitute a major loss of ethanol yield. Use of genetically modified yeast that can simultaneously convert glucose and xylose to ethanol has been reported (Ho, 2004). Presently we are focusing this new research direction.

Effect of alkaline hydrolysis using $0.25 \mathrm{M}$ sodium hydroxide and saccharification of bitter kola pulp wastes on concentration of reducing sugar is presented in Figure 4. Alkaline hydrolysis had no significant effect on concentration of reducing sugar. This could be due to the fact that sodium hydroxide was more effective at solubilizing a greater fraction of lignin while leaving behind much of the hemicellulose in insoluble polymeric form. Ethanol was also produced after two hours alkaline hydrolysis of bitter kola pulp wastes and saccharification with $A$. niger using EMCEferm yeast. Ethanol produced $(\mathrm{g} / \mathrm{L})$ for both alkaline hydrolysed and control increased to maximum value of $5.6 \mathrm{~g} / \mathrm{L}$ at $96 \mathrm{~h}$ and then increased to maximum of $6.4 \mathrm{~g} / \mathrm{L}$ at $144 \mathrm{~h}$ and $168 \mathrm{~h}$ respectively. Alkaline hydrolysis has no significant effect on ethanol yield.

Effect of invertase supplementation is presented in Table 1. Invertase supplementation enhanced the production of reducing sugar from bitter kola pulp wastes with time. Acid treatment decreased the time of optimal sugar production to $48 \mathrm{~h}$ for the bitter kola pulp wastes and maize husks. However rice husks had optimal sugar production at $120 \mathrm{~h}$

\section{Conclusion}

This study revealed that acid hydrolysis with $2.5 \mathrm{M}$ sulphuric acid and saccharification using $A$. niger significantly optimized ethanol production from bitter kola (G. Kola) pulp wastes. Alkaline hydrolysis had no significant effect on ethanol yield. Bakers yeast performed better than EMCE-ferm yeast. Furthermore, solar drying of the agro-waste has significant positive effect on the optimization of ethanol yield. 
Table 1. Effect of invertase supplementation after acid hydrolysis with sulphuric acid and saccharification with Aspergillus niger on bitter kola pulp compared with maize and rice husks.

\begin{tabular}{|c|c|c|c|c|c|c|}
\hline & \multicolumn{3}{|c|}{ Control } & \multicolumn{3}{c|}{ Acid hydrolysed } \\
\cline { 2 - 7 } Time (h) & $\begin{array}{c}\text { Bitter kola } \\
\text { pulp }\end{array}$ & Maize husks & Rice husks & $\begin{array}{c}\text { Bitter kola } \\
\text { pulp }\end{array}$ & Maize husks & Rice husks \\
\hline 24 & $13.2 \pm 0.4$ & $8.5 \pm 0.4$ & $5.6 \pm 0.4$ & $22.1 \pm 0.4$ & $17.4 \pm 0.4$ & $14.4 \pm 0.4$ \\
48 & $13.8 \pm 0.2$ & $10.3 \pm 0.3$ & $10.9 \pm 0.3$ & $23.2 \pm 0.3$ & $22.7 \pm 0.3$ & $15.6 \pm 0.3$ \\
72 & $14.4 \pm 0.4$ & $7.9 \pm 0.4$ & $11.5 \pm 0.4$ & $20.3 \pm 0.4$ & $18.0 \pm 0.4$ & $16.8 \pm 0.4$ \\
96 & $15.6 \pm 0.4$ & $7.4 \pm 0.4$ & $13.2 \pm 0.4$ & $18.0 \pm 0.4$ & $16.8 \pm 0.4$ & $20.3 \pm 0.4$ \\
120 & $16.8 \pm 0.3$ & $6.8 \pm 0.3$ & $14.4 \pm 0.3$ & $16.2 \pm 0.4$ & $14.4 \pm 0.3$ & $21.5 \pm 0.3$ \\
144 & $17.4 \pm 0.4$ & $8.5 \pm 0.4$ & $16.8 \pm 0.4$ & $15.0 \pm 0.3$ & $13.8 \pm 0.4$ & $18.0 \pm 0.4$ \\
168 & $18.0 \pm 0.4$ & $10.3 \pm 0.4$ & $17.4 \pm 0.4$ & $14.4 \pm 0.3$ & $15.6 \pm 0.4$ & $19.1 \pm 0.4$ \\
192 & $19.1 \pm 0.3$ & $10.9 \pm 0.3$ & $18.5 \pm 0.4$ & $12.7 \pm 0.4$ & $12.7 \pm 0.3$ & $17.4 \pm 0.3$ \\
216 & $17.4 \pm 0.4$ & $11.5 \pm 0.4$ & $18.5 \pm 0.4$ & $15.6 \pm 0.4$ & $13.2 \pm 0.4$ & $15.9 \pm 0.4$ \\
\hline
\end{tabular}

Results are expressed as means \pm SD of duplicate analysis.

\section{REFERENCES}

Abd El-Nasser NH, Helmy SM, El-Gammal AA (1997). Formation of enzymes by biodegradation of agricultural wastes with white rot fungi. Polym. Degrad. Stab. 55: 249-255

Aiello C, Ferrer A, Ledesma A (1996). Effect of alkaline treatments at various temperatures on cellulase and biomass production using submerged sugarcane bagasse fermentation with Trichoderma ressei QM9414. Bioresour. Technol. 57: 13-18

Akin-Osanaiye BC, Nzelibe HC, Agbaji AS (2005 a) Production of ethanol from Carica papaya (Pawpaw) agro waste: Effect of saccharification and different treatments on ethanol yield. Afr. J. Biotechnol. 4(7): 657-659.

Akin-Osanaiye BC, Nzelibe HC, Agbaji AS (2005b) Production of ethanol from Garcinia kola (Bitter kola) pulp wastes using Saccharomyces cerevisiae (Baker's yeast). J. Trop. Bio. Sci. (In press).

Analyst (2006). Alternative energy for the US, George W Bush State of the Union speech Analyst Brazil.

Bilford EA (1942). Alcoholic fermentation of molasses. Ind. Eng. Chem. 24: 1406.

Bose K, Ghose Tk (1973). Studies on continuous fermentation of Indian cane Sugar molasses by yeast, Process Biochem. 10: 60 .

Chen S, Waymann M (1991). Cellulase production induced by carbon sources derived from waste newspaper. Process Biochem. 26: 93100.

Dahot MU, Noomrio MH (1996): Microbial production of cellulases by Aspergillus fumigatus using wheat straw as a carbon source. J. IAS, 9(4): 1-5.

D'Amarc T, Stewart G (1987). Ethanol tolerance of yeast, Enzyme Microb Technol. 9: 322-330.

Days DL (1989). Biomass waste. In: Biomass Handbook, ed. Kitani O, Hall CW, pp. 268-277. New York; Gordon and Breech.

Doppelbauer R, Esterbauer H, Steiner W, Lafferty, R, Steinmuller H (1987). The use of cellulosic wastes for production of cellulases by Trichoderma reesei. Appl. Microbiol. Biotechnol. 26: 485-494

Ho N (2004). Purdue yeast makes ethanol from agricultural waste more effectively Purdue News June 28.

Hsu TA (1996). Pretreatment of biomass. In: Wymann, C.E. (ED), Handbook on Bioethanol: Production and Utilization. Taylor \& Francis, Washington, DC, pp. 179-212.

Kawamori M, Morikawa Y, Ado Y, Takasawa S (1986). Production of ethanol. from biomasses.Part IV. Production of cellulases from alkalibagasse in trichoderma reesei. Appl. Microbiol. Biotechnol. 24: 454458.
Ladisch MR (1989). Hydrolysis in Biomass handbook, ed. O. Kitani CW. Hall. 434 - 451. New York: Gordon and Breech.

Maheshwari DK, Gohade S, Paul J, Varma A (1994). Paper mill sludge as a potential source for cellulase production by Trichoderma reesei. QM9123 and Aspergillus niger using mixed cultivation. Carbohydrate Polym. 23: 161-163

Mani S, Tabil LG, Opoku A (2002). Ethanol from agricultural crop residues - An overview. The society for engineering, food and biological systems. MBSK 02- 217. An ASAE/CSAE Meeting presentation.

Miller GC (1959). Use of the Dinitrosalicylic Acid Reagent for the determination of reducing sugar. Anal. Chem. 31: 420-428.

Okafoagu CU, Nzelibe HC (2006) Effect of acid hydolysis of Garcinia kola pulp waste on the production of $\mathrm{CM}$-cellulase and B-glucosidase using A niger, .Afr. J. Biotechnol. 5(10): 819-822.

Reczey K, Szengyel ZS, Eklund R, Zacchi G (1996). Cellulase production by T.reesei. Bioresour. Technol. 57: 25-30.

San Martin R, Blanche, WH, Wilke RC, Sciamanna FA (1986). Production of cellulase enzymes and hydrolysis of steam-exploded wood. Biotechnol. Bioeng. 28: 564-569.

Shipnei M, Kume T, Hashimoto S (1995). Effects of gamma-irradiation on enzymatic digestion of oil palm empty fruit bunch. J. Sci. Food Agric. 69: 265-267

THISDAY (2006). Federal Government of Nigeria takes over 400 Billion Naira Ethanolmroject. Thisday Newspaper Thursday Feb 2 vol 11(3939): 11.

Wang MC, Saricks D, Santini (1999). Effects on fuel ethanol use on fuel-cycle energy and green house gas emissions. Agronne National Laboratory, Agrone, IL.

Wayman M, Chen S, Doan K (1992) Bioconversion of Waste paper to ethanol. Process Biochem., 27: $239-245$.

Xu P, Thomas A, Gilson CA (1996) Combined use of three methods for high concentration ethanol production by Saccharomyces cerevisiae. Biotechnol. Lett. 18(2): 1439-1440. 